\title{
Engaging in homework development: TARSIS platform as an innovative learning methodology
}

\author{
Francisco Buitrago-Flórez, Juan C. Reyes, Raul Rincón, Carola Hernández, Francisco A. Galvis ${ }^{\text {a }}$ \\ Christiam Ángel \\ Universidad de los Andes, ${ }^{\text {a }}$ Stanford University
}

\begin{abstract}
Homework assignments in engineering courses are still passive learning instruments that often appear as requirements rather than learning tools. This issue arises because the teaching team usually does not have the capabilities to provide real-time feedback, or to enable students to fix errors in a timely manner. To overcome this challenge, we developed a novel blended-like methodology for homework assignments called TARSIS. This methodology uses a platform to boosts the contribution of homework assignments in the learning process by using a non-penalised attempt mechanism for online solutions, combined with a real-time feedback scheme in both virtual and face-to-face environments. In this study, we describe the methodology and use mixed-method research to assess the performance of TARSIS. Performance data were compared quantitatively with a previous cohort. Moreover, openended questions from surveys, interviews, and data from focus groups were qualitatively analysed. Results indicate that students enrolled with TARSIS achieved higher performance in both homework assignments and exams. Furthermore, students' perceptions demonstrate higher enthusiasm and motivation towards the value of homework assignments as mechanisms to promote learning. Effectiveness related to the attempt mechanism and realtime feedback is subsequently explained under key concepts of the socio-cultural vision of education such as reification and participation.
\end{abstract}

Implications for practice or policy:

- Use of information and communication technology to facilitate active learning.

- Inclusion of active learning in homework assignments development.

- A socio-cultural vision of homework assignments for students' performance improvement.

Keywords: homework assignments, active learning, online platforms, socio-cultural vision of education, mixed method research

\section{Introduction}

During the past decades, several studies have revealed that traditional teaching in engineering courses does not result in the desired learning outcomes (Carr, Palmer, \& Hagel, 2015; Pundak \& Rozner, 2008). Furthermore, research shows that students in effective learning environments must have an active role in class, rather than being passive listeners in a lecture (Felder \& Brent, 2016; Hernández, Ravn, \& Valero, 2015; Radford, 2008). Consequently, active learning has received considerable attention over the past years. Given that active learning places students at the centre of the learning environment, apprentices are able to move beyond learning objectives related to content to develop abilities in critical thinking, leadership, communication, and ethical decision making (Hall, Waitz, Brodeur, Soderholm, \& Nasr, 2002). In engineering, however, on-going teacher-centred practices continue to be the most popular strategy (Carr et al., 2015; Henkel, 2005). In order to generate a change in pedagogical approaches, teachers need to invest time to develop, implement, and evaluate new learning strategies, as well as integrate modern technologies into the classroom.

Given their potential in learning environments, homework assignments have been an issue of controversial discussion and research for some years (Fan, Xu, Cai, He, \& Fan, 2017). There are numerous benefits for students by doing such activities in terms of problem solving and critical thinking (Hailey, 2018). However, the lack of feedback and face to face interactions lead to a limited development of key skills amongst students (Pundergast, Watkins, \& Canivez, 2014). Therefore, students often envision homework assignments as mandatory tasks to accomplish or activities to obtain informal grades. As technological advances in education arrived, several platforms were developed as a way to facilitate the development of homework assignments; however, online-based methods are unable to offer detailed feedback and might fail to increase motivation among students (Zare, Cox, Murphy, \& Bayas, 2017). Blended strategies are 
showing high success rates in learning and teaching by combining the best of digital and traditional forms of education. Such strategies provide the mechanisms to promote active learning in students through autonomous activities and discipline-based as well as deep face to face discussions with teachers and peers (Havemann \& Barros, 2019). Therefore, this research study explores the performance of a novel blendedlike methodology which includes socio-cultural concepts of education for the development of homework assignments.

\section{Literature review}

\section{Active learning and the socio-cultural theory of education}

As defined by Felder and Brent (2016), active learning is a set of activities that are carefully designed for individuals or small groups to ensure full engagement of all students. These activities often alternate from student-working tasks to teacher-led moments, where the instructor analyses student outcomes in front of the class and presents new information in an iterative form. Active learning relies on high student engagement to promote the building of knowledge. Therefore, active learning is fully encompassed within the socio-cultural theory of education as described by Vygotsky (1978). This perspective of learning, as discussed by Radford (1997), proposes that knowledge is the product of meaning negotiation, framed by activities of individuals in a cultural context. In other words, learning occurs as a specific social process, in which the learner becomes progressively expert in cultural forms of thinking through the mastering of language, interactions, signs and artifacts (Radford, 2008). Socio-cultural approaches in education claim that learning is a complex process which is the product end of different activities, contexts, and sociocultural factors involving the learner (Wertsch, 1985). As such, it is plausible to state that the origins of human thinking may be inseparable from social and cultural practices (Hernández et al., 2015).

Embracing a socio-cultural perspective in education indicates that researchers and practitioners must envision education processes as social activities developed in communities (Leach \& Scott, 2003). Therefore, learning must not be considered as an isolated and individual process; on the contrary, it must be understood as a distribution and transformation among members of a community of practice (Wenger, 1998). For Wenger, the term community of practice derives from the notion of learning as active social participation and relies on the idea that the learning process occurs when people who have a common practice share ideas, values, beliefs, languages, and ways of doing in an extended period of time (Hernández et al., 2015). Therefore, under the socio-cultural theory of education, it seems reasonable that promoting pedagogical student-centered approaches enables students to actively take part in social processes to elaborate on knowledge.

This vision of education allows students to be the centre of their own active learning process, thereby involving the learners in actual activities of the community of knowledge. This concept is far different than traditional teacher-centered strategies, in which teaching is seen as a process of transmission from the teacher to the students not only of information, but also concepts, skills, and competencies (Roth \& Lee, 2004). As described by Wenger (1998), under the socio-cultural vision of education, students enter into a community of learning, in which a member gets involved in participation (actively interacting and creating identity in the community) and reification (transforming abstract information into real artifacts), and progressively builds significant knowledge in the process. In this sense, the role of the professor changes from the source of knowledge to be supposedly transmitted, to an experienced member of the community who helps the students in the process of becoming active members of it (Radford, 2008).

\section{Use of information and communication technologies resources for active learning}

One way of promoting active learning among students is through an appropriate and well-developed use of information and communication technologies (ICT) resources. Internet technologies might enable students to promote active and independent learning trough reflection, as well as support the most relevant communication between experts and novices as they can access up-to-date information anywhere and anytime (Havemann \& Barros, 2019; Ping, 2004). Encouraged by these opportunities for student learning, several educational institutions have put their efforts into getting enough bandwidth for online learning, buying specific courseware, and acquiring the latest online platforms and tools. Nevertheless, research has shown that software and hardware infrastructure just provide the conditions for passive online enrollment (Tayebinik \& Puteh, 2012). Unfortunately, these sorts of resources do not ensure either that learners are 
going to engage in the processes of learning in context, or that they will construct their own knowledge based on the provided information (Broadbent, 2017).

While it is certain that online environments may provide students with multiple occasions to enroll themselves in learning processes, it cannot be assumed that these opportunities will be exploited (Gomez \& Duart, 2011). Two critical problems in e-learning arise regarding engagement. On the one hand, online courses fail to accommodate learning processes to a few students, which may create a cognitive overload for learners leading to disengagement (Broadbent, 2017; Clarck \& Maryer, 2002). Note that a cognitive load may be defined as the level of mental energy required to process a given amount of information (Ping, 2004). On the other hand, online courses fail to show the relevance of concepts and theories presented to the learners, also causing disengagement. Moreover, students may display a lack of learning strategies in order to approach the online learning component, as this digital strategy offers a multiplicity of options that again can cause cognitive overload. Hence, appropriate learning materials should promote learning by directing cognitive resources towards activities that are relevant and in context for the learner, rather than annexed processes of the instructional setting (Perera, 2010). Even the most proficient learners can lose motivation if too much effort is required to navigate interactive elements of the online component and using supporting tools. Such excessive supplemental work diminishes the mental resources for comprehension and achievement of the learning objectives (Garrison \& Vaughan, 2013).

Several studies have described another major disadvantage of e-learning environments related to the suppression of socialisation among individuals, causing a lack of face-to-face communication (Dziuban, Graham, \& Moskal, 2018; Harrington, 2010; Lim \& Morris, 2009). Based on Wenger (1998) and framed by the socio-cultural theory of education, such a lack of socialisation could promote excessive processes of reification. Hence, it generates a considerable decrease in participation, which then leads to an unsuccessful process of significant meaning construction in students. In response, a recent environment that combines the digital and traditional modes of learning has emerged under the name of blended learning (Tayebinik $\&$ Puteh, 2012). The foremost goal of blended instruction is to overcome the drawbacks of pure online instruction and promote active learning. As stated by Garrison and Vaughan (2007), blended learning represents a complete rethinking and redesign of how we approach learning and teaching, generating a coherent scheme and integrating the strengths of face-to-face and online approaches to address worthwhile educational goals. Moreover, blended instruction offers flexible learning scenarios and frees up time for faculty members to spend with novices in small groups or even individually (Garrison \& Vaughan, 2013; Oh \& Park, 2009).

\section{The importance of homework in active learning}

Homework assignments are required in undergraduate classes since they can have a significant positive effect on student learning. Homework assignments enhance interpretative skills (Fan et al., 2017; Xu, Benson, Mudrey-Camino, \& Steiner, 2010), promote the development of good study habits and skills (Cooper, 2001b), improve learning (Ramdass \& Zimmerman, 2011), prepare students for exams, and reinforce concepts learnt in the course (Cooper, 2001a). However, several researchers have reported a negative student attitude towards homework assignments, which undermines their benefits as a learning instrument (Kravolec \& Buell, 2011; Pundergast et al., 2014; Shunk, 2001). Specifically, students do not envision these as a functional activity for learning. On the contrary, they often see this sort of activity as a standard requirement that might help to obtain higher grades, as well as a task to be solved in as little time as possible. Homework assignments could be projected as mechanisms to foster participation and reification under the socio-cultural vision of education. Students engaged in individual and auto-regulated activities could actively participate as active members of a community of learning, inquiring into specific aspects in which they have to display mastery, and interacting with peers and teachers to fulfill learning objectives (Felder, 2007; Roth \& Lee, 2004; Sutherland, Scanlon, \& Sperring, 2005).

There are numerous platforms for homework assignments available, yet, not all of them are effective. Several aspects, including immediate feedback, pace for teachers and students, and time consuming for teachers must be considered at the time of implementation of online tools (Heffernan, 2019). Nevertheless, there is no literature associated with a deep analysis of blended-like approaches for homework assignments framed within structural educational concepts such as reification and participation. These processes would add a reflective component that undoubtedly leads to a deeper understanding of concepts, as well as to a personal development of mechanisms and strategies for learning. To effectively promote homework assignments as participation and reification opportunities, teachers and stakeholders must assure that 
students perceive them as a crucial learning mechanism, offering pedagogical designs that boost motivation and avoid disengagement and fraud.

This study describes the design, implementation, and evaluation of a novel blended-like methodology for homework assignments development called TARSIS. This methodology boosts the contribution of homework assignments in the learning process by using an online attempt mechanism solution, combined with a real-time feedback scheme in both virtual and face-to-face environments. Such characteristics were designed to stimulate reification and participation in learners to contribute effectively to their building of knowledge.

\section{Research questions}

1. What is the impact of TARSIS' methodology on student performance?

2. Which factors motivate students to consciously use the TARSIS methodology for homework assignments?

\section{Method}

\section{Setting, TARSIS platform, and TARSIS methodology}

Data was retrieved from a structural analysis course at Universidad de los Andes, Colombia. This course is a mandatory class for fifth semester students of the civil engineering undergraduate program. Undergraduates meet three times a week, twice for lectures and once for a hands-on laboratory ( 80 minutes each session), for 15 weeks. The number of students enrolled in the course varies from 80 to 120 every semester, with ages ranging from 18 to 22 years. Their performance is evaluated via 7 individual homework assignments (15\%), 3 individual written tests (75\%), and 14 laboratory assignments $(10 \%)$.

Grading homework assignments is one of the most demanding activities in these sorts of courses, as this action relies on a manual process. In spite of the enormous effort, students often describe the homework assignments' feedback as slow and ineffective, as a consequence of obtaining it several days (or weeks) after they deliver the assignment. Therefore, they never have the chance of getting real-time feedback to fix errors and improve their grade, which leads to frustration, disinterest, and disengagement. Furthermore, academic fraud is a rising concern among teachers since there is evidence that a reduced group of students systematically share homework answers. In developing countries, additionally, the perception of seriousness of academic fraud might be described as shallow (Malgwi \& Rakovski, 2009).

In response to these problems, we developed a learning approach denominated as TARSIS methodology. This methodology uses the socio-cultural concepts of reification and participation, in combination with an online platform for systematised homework assignments, called TARSIS (http://tarsis.uniandes.edu.co). TARSIS methodology allows students to reflect upon their errors as an essential and critical part of the process of learning. The power of the approach relies on the idea that the apprentice can stop and request virtual or face-to-face personalised support at any specific step of the homework assignment, making the interaction between students and teaching staff very efficient. Once the students have clarified their questions, they are able to return to the platform to finish their homework or request further support in a subsequent problem. Furthermore, the TARSIS platform assigns individual problem situations to each student in order to discourage fraud. Each problem is disaggregated in small steps denominated items, designed to coherently walk the student through each problem. Every item has multiple attempts, so the student has several opportunities to obtain the maximum grade.

The TARSIS platform is logically organised into three main roles: (1) the administrator, (2) the professor, and (3) the student. Figure 1 represents the deployment diagram of TARSIS platform, the different roles, and their relationships. The administrator is a unique role with granted permissions for modifying the frontend (public and visible) and the back-end (logical and functional area) of the platform. The professor role is the one designated for professors and teacher assistants. They are responsible for creating the student role, the group sections (each one represents a group of students enrolled in a structural analysis course), and the content (homework assignments). For aggregated analysis, TARSIS conducts a basic statistical analysis of the number of attempts made and grades obtained by students, and is able to provide summary charts per student, per section, or per homework assignment. 


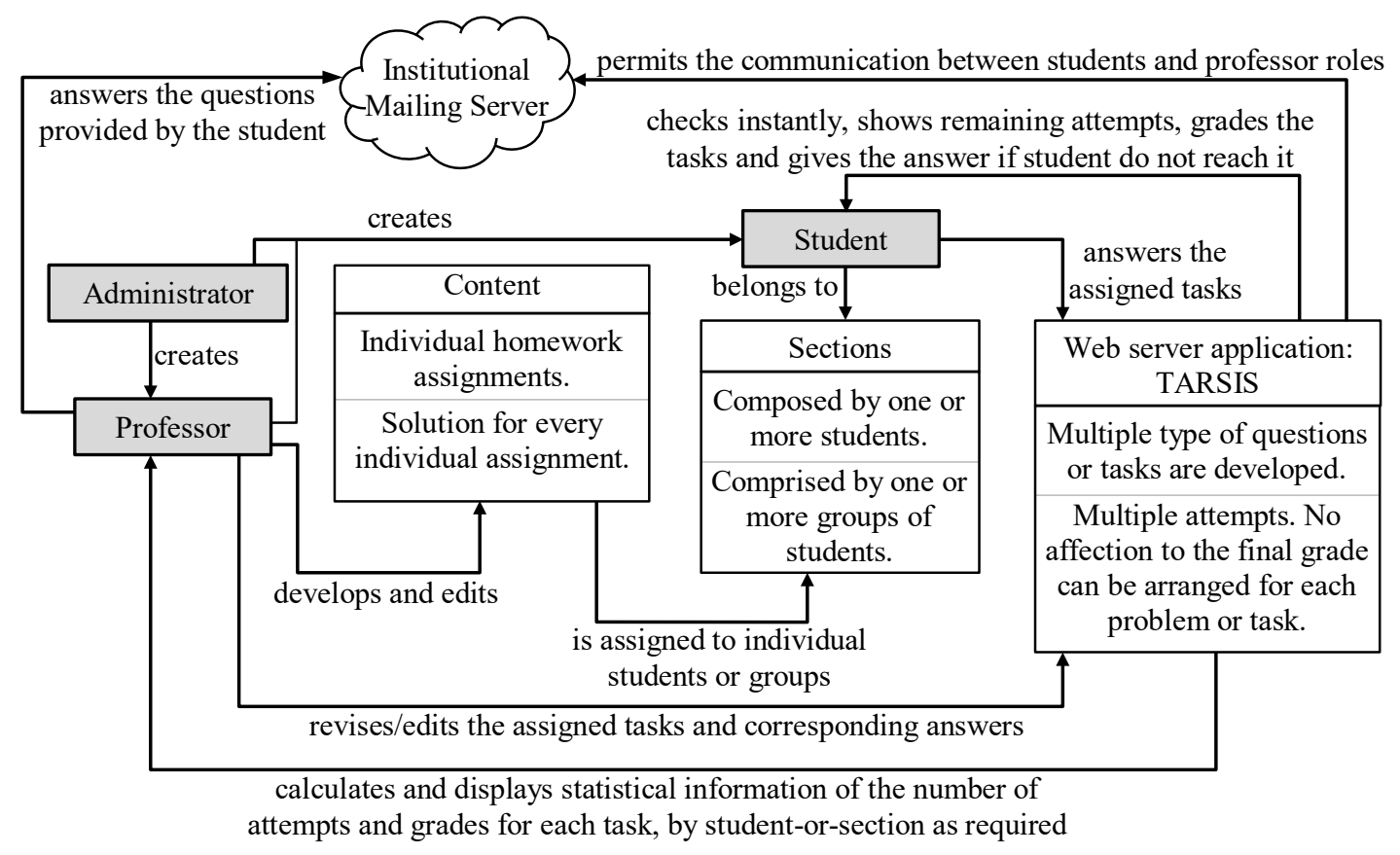

Figure 1. Roles and deployment diagram of the TARSIS platform

\section{Evaluation design and data collection}

As proposed by Bamberger (2012), evaluation is comprehended in this research study as the systematic collection of information regarding characteristics, activities, and results of pedagogical interventions. Analyses of such data allow stakeholders to increase their understanding about design and implementation, in order to take informed decisions for improvement or further development of educational programs. Following Cresswell's (2009) description of concurrent mixed-methods, the research design of this study includes open and close-ended approaches for data collection. Given the research questions of this study, we were interested in analysing student's performance (in homework assignments and the overall course), as well as students' perception regarding TARSIS methodology, motivation and repercussion in learning. Therefore, we performed a quantitative analysis of data associated with homework and overall course performance before and after TARSIS methodology deployment (cohort comparison), and closed-ended questions from questionnaires were analysed quantitatively. In addition, qualitative data was collected through students' focus groups, open questions from surveys and interviews with the teaching team, aiming to inquire about motivation and repercussion in learning. As such, interviews and open question surveys offered explanation of internal thought processes and experiences of individuals as interpretative visions (Merriam \& Tisdell, 2015). Moreover, focus groups allowed for the interaction of participants, providing a comfortable environment to express their opinions and perceptions in a deep discussion of a shared experience (Lecanda \& Garrido, 2003). The techniques used for data collection in this research provided a degree of triangulation that permits establishing the validity and reliability of the conclusions derived from the evaluation process (Oliver-Hoyo \& Allen, 2006). An integration of statistical and narrative analyses was used to investigate student experiences, performance, and perceptions, while keeping with the pragmatic methods promoted by mixed-methods proponents (Green, Bouce, \& Ahn, 2011; Tashakkori \& Teddle, 2002).

\section{Quantitative phase}

Quantitative information about student's performance in homework assignments and overall course grades was collected for all students enrolled in the first semester of $2019(N=81)$. The same data was retrieved from a previous cohort (first semester 2017, $N=89$ ) without a TARSIS methodology intervention. Comparison of these data sets allowed us to determine the impact of our novel methodology. Additionally, students' perception about the TARSIS methodology was retrieved via closed-ended questions in a survey answered by all 81 students enrolled in the TARSIS cohort. This survey asked about the levels of satisfaction, rate of use, difficulties, promotion of motivation, efficiency and efficacy of feedback, and rate 
of use of virtual and face-to-face personalised attention. Data from students retaking the course or those who unenrolled at some point of the semester were removed before analyses.

\section{Qualitative phase}

Perceptions of the students were retrieved via open-ended questions in a survey and two focus groups. Questions in both instruments inquired about the impact of the TARSIS methodology in terms of multiple aspects such as the development of homework assignments, active learning, performance in exam, and possible aspects for future improvement. Moreover, structured interviews were carried out with teachers and teacher's assistants, inquiring about their view regarding students' attitudes towards the implementation of TARSIS methodology. All students and teachers signed informed consents for data gathering as required for the ethics committee of the institution.

\section{Quantitative analyses}

The impact of the TARSIS platform in student's performance was measured by comparing data from two cohorts. Statistical comparisons were made to visualise the distribution of performance for each cohort through boxplots, as well as for visualisation of individual grades' frequencies for the homework assignments and the final grades. Additionally, to categorise the performance in a 5-point scale, students' grades were grouped in the following intervals: [0.0 - 3.0), [3.0-4.0), [4.0 - 4.5) and [4.5 - 5.0], being 5.0 being the highest possible grade. These intervals correspond to not mastered, limited mastered, mastery, and high performance, respectively. A statistical $T$-test for equal means without assuming equal variances analysis in homework assignments and overall grades was carried out using MATLAB software (MATLAB, 2019) between the two cohorts, aiming to find out significant differences. Moreover, the mean number of student's attempts per item was analysed for each homework assignment to understand statistical tendencies in the performance of students regarding homework assignments with TARSIS. Finally, data from surveys were organised in terms of the frequency of students within each answer category, and subsequently presented for each question using horizontal bar charts.

\section{Coding methodology}

We used a two-phase process to categorise and analyse our interpretive data. In both phases, we developed a coding scheme using a priori and emergent qualitative techniques (Cresswell, 2009). This method summarises data and determines first-level coding to obtain general categories from the complete data set. Phase I focuses on three pre-established categories: (a) motivation for using TARSIS methodology; (b) perception regarding the feedback provided, and (c) perception regarding repercussion in learning given the methodological innovation. Data coding and analysis happened simultaneously as the interpretive data were reviewed. In Phase II, we developed smaller categories from the Phase I data set via emergent coding. We intended to categorise participant interventions that targeted motivational reasons, explanations for use, quality of feedback and explanations for better learning processes throughout the course. Initially, a single researcher coded all the data in the emergent sub-categories. After the initial coding, each researcher performed a review process, with subsequent meetings carried out to reach a point of agreement.

\section{Results}

\section{Performance}

Statistical performance of students (mean, median, and standard deviation) prior and after implementation of TARSIS methodology is displayed in Figure 2 and Table 1. White boxes represent the traditional cohort (2017-1) and filled boxes represent the TARSIS cohort (2019-1). Homework assignments and final grades medians were $4.4 \%$ and $5.1 \%$ greater in the TARSIS cohort, respectively. Standard deviation (STD) increased $65 \%$ for homework assignments grades in TARSIS cohort; however, the STD of the final course grades were nearly the same in both cohorts. Although the STD of homework assignments increased in the TARSIS cohort, the 25- and 75-percentile grades were greater in homework assignments, meaning that a significant proportion of students achieved better performance. 


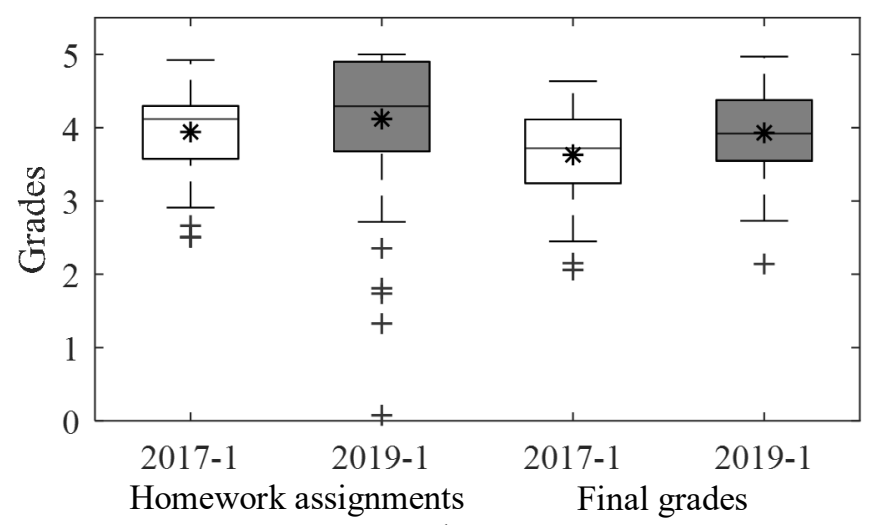

Figure 2. Statistical results for homework assignments and final grades. The median is represented in the figure as a solid horizontal line inside the boxes, the mean is represented as an asterisk, the percentiles 25 and 75 are represented as the two solid horizontal lines at the border of the boxes, and the outliers are shown as crosses. The numerical means, STD and medians are summarised in table 1.

Table 1

Summarised central tendencies and variation for the two cohorts

\begin{tabular}{lcccc}
\hline Item & Cohort & Mean & STD & Median \\
\hline Homework & $2017-1$ & 3.94 & 0.56 & 4.12 \\
assignments & $2019-1$ & 4.12 & 0.92 & 4.29 \\
\hline \multirow{2}{*}{ Final grade } & $2017-1$ & 3.63 & 0.58 & 3.72 \\
& $2019-1$ & 3.93 & 0.57 & 3.92 \\
\hline
\end{tabular}

Figure 3 shows the cumulative curves for homework assignment grades and final grades in the two considered cohorts. Cumulative curves were developed by organising the students' grades from the lowest to the highest grade obtained. Then, each student grade was plotted against the normalised position by the total of students in the course. Only grades ranging in between 3.0 and 5.0 are shown to emphasise the effect of the students who approve. This range was chosen since one of the main objectives of TARSIS methodology is to improve the performance of students through the understanding of concepts, rather than offering low effort ways to increase grades in the course. Figure 3 shows that TARSIS methodology improves the students' grades distribution. For instance, $41 \%$ of students obtained grades of 4.5 or higher in homework assignments during 2019-1, while in 2017-1 only 12\% of students achieved such performance. This result demonstrates that almost half of the students reached a high performance level in the TARSIS cohort (Figure 3a). Likewise, the failing percentage (fraction of students with a grade lower than 3.0) dropped from $16 \%$ in $2017-1$ to only $5 \%$ in $2019-1$, as shown in figure $3 \mathrm{~b}$. Additionally, it became clear that final grades for the TARSIS cohort were higher compared with the similar percentile of students evaluated in the previous cohort.
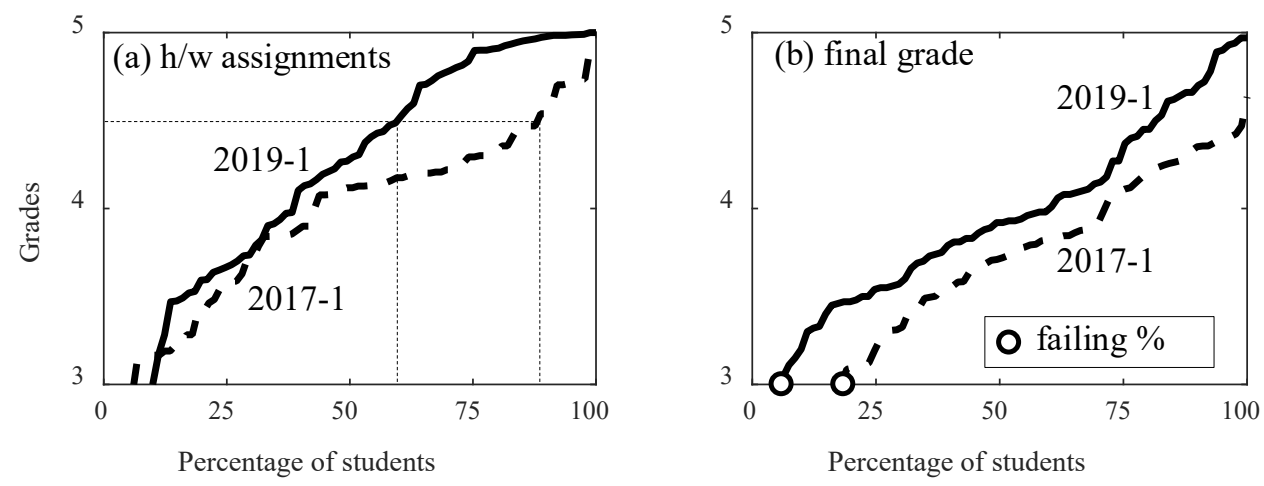

Figure 3. Cumulative curves of final grades: (a) homework assignments and (b) final grade. 2019-1 cohort is represented by a solid black line and 2017-1 cohort by a dashed one. Failing percentage is represented as open circles for both cohorts in figure $3 b$. 
For simplicity and more straightforward comparison of student's performance, the 5-point grade scale was categorised in four performance intervals: $[0.0-3.0),[3.0-4.0),[4.0-4.5)$ and $[4-5-5.0]$. Figure 4 summarises the percentage of students in each category, confirming that TARSIS cohort displays better performance in comparison to the traditional course. Figure 4 shows, additionally, that the number of students located in the high-performance interval (grades above 4.5) increased about 2.4 times for homework assignments, as well as 19 times for final grades when enrolled in the TARSIS methodology.
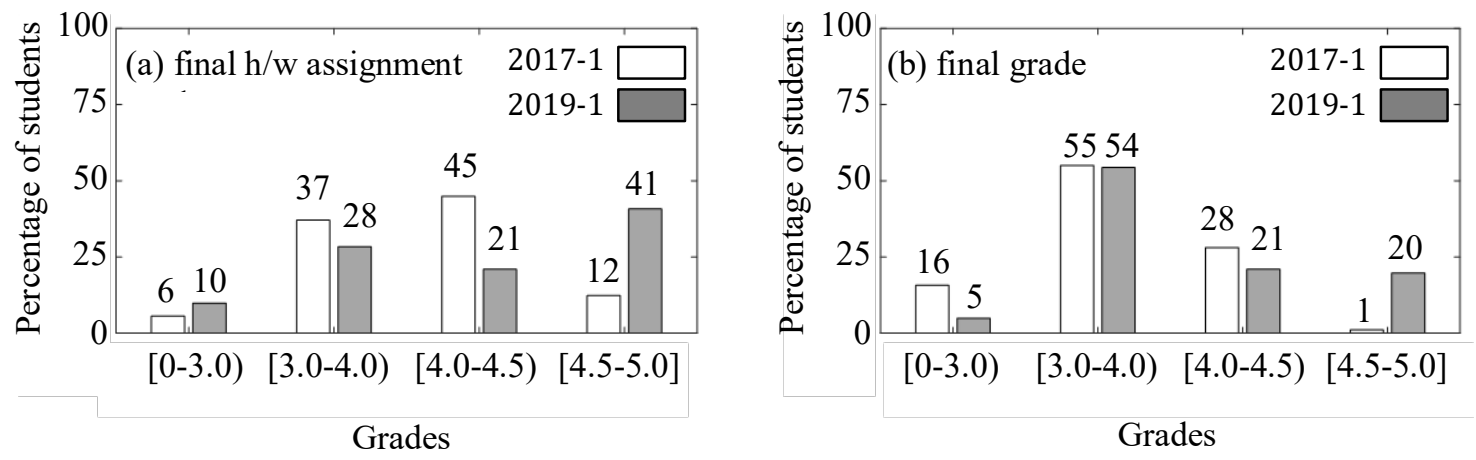

Figure 4. Grouped results of students: (a) final homework assignments; and (b) final grade.

Moreover, T-test results demonstrated, with a 95\% confidence level, that the two analysed cohorts may assume a significant difference regarding the final grade $(p<.001)$. Moreover, homework assignments grades did not show a significant difference $(p>.01)$. Thus, it is clear that TARSIS significantly improved the students' performance in comparison with the traditional approach. As mentioned earlier, the final grade is a dependent variable, with $75 \%$ of its total comprised of individual written tests. Therefore, the final grade relies on the individual students' performance, without any external help (books, professors, other students, etc.).

As described, data indicates a significant increase in the proportion of students in the high performance level. Nonetheless, we considered it necessary to evaluate to what extend this result can be attributed to the multi-attempt functionality of TARSIS. Figure 5a presents the distribution of the mean number of attempts per item in each homework assignment. Data revealed that students commonly stop using non-penalised attempts before they were over and proceeded to use virtual or face-to-face personalised support. Figure 5a shows that students typically required - or used - no more than three attempts (according to the median value) to solve each of the sub-items. It is important to state that Figure 5a only includes students that did not reach the last attempt, in order to highlight the behaviour of the students that correctly solved each item. Finally, it was found that a portion of the students stopped working on homework assignments at the end of the semester. Figure $5 \mathrm{~b}$ shows that assignments 1 to 5 were done by about $95 \%$ of the class, while participation in assignments 6 and 7 was reduced by between $10 \%$ and $20 \%$. This behavior was somehow expected since students decide to prioritise projects and exams over homework assignments as the end of the semester approaches. 

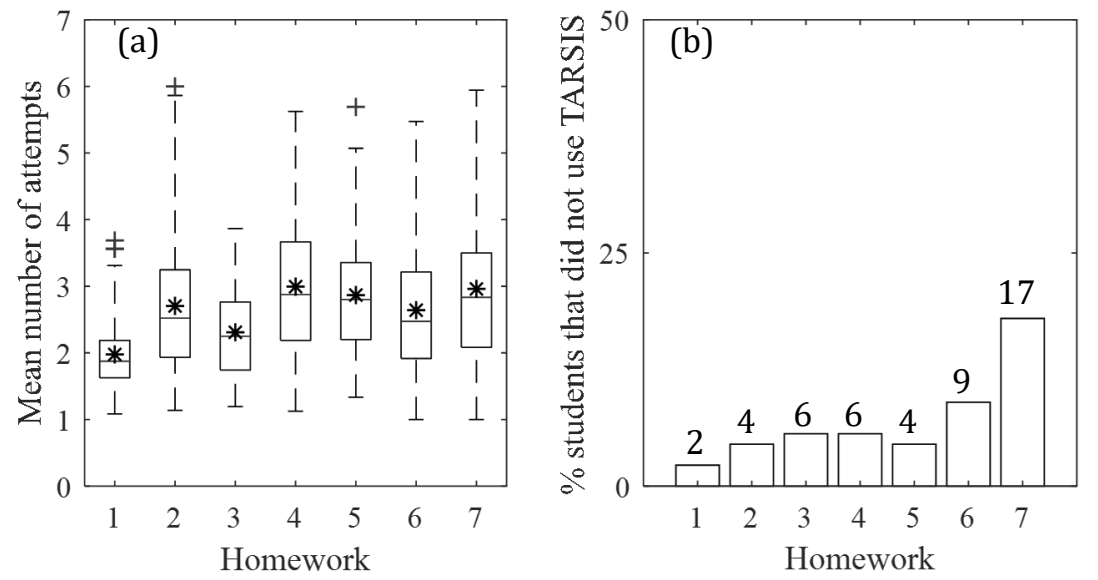

Figure 5. Analysis of attempts: (a) normalised mean number of attempts; and (b) percentage of students that did not use TARSIS in each homework.

\section{Perception}

The students' perception was collected anonymously using eight multiple choice questions inquiring about the level of students' satisfaction, rate of use of the TARSIS platform, and opinions about the system's performance. Figure 6 presents each question and summarises the results. All the students' answers were considered, including those who were repeating the course. Answers to questions (a) and (b) show a remarkable positive perception about TARSIS, with $92 \%$ of the surveyed declaring to be very satisfied with the platform and $96 \%$ perceiving as good or excellent the performance of the platform. Answers to question (c) show that more than $95 \%$ of students used the platform and combined it with the face-to-face assistance to solve questions. It is noteworthy that only $10 \%$ of students never used the face-to-face assistance as depicted in question (d). Questions (e) and (f) asked students about self-consciousness of their learning process, which reveals that most of them agreed that the TARSIS capabilities of instantaneous feedback and multiple attempt system, improved their performance and learning. Question $(\mathrm{g})$ inquired about the principal difficulties that students encountered while enrolled in TARSIS, showing that some minor technical problems were the biggest concern. Finally, a total of $82 \%$ of the surveyed considered that TARSIS reduced fraud in homework assignment development, as displayed in question (h). 


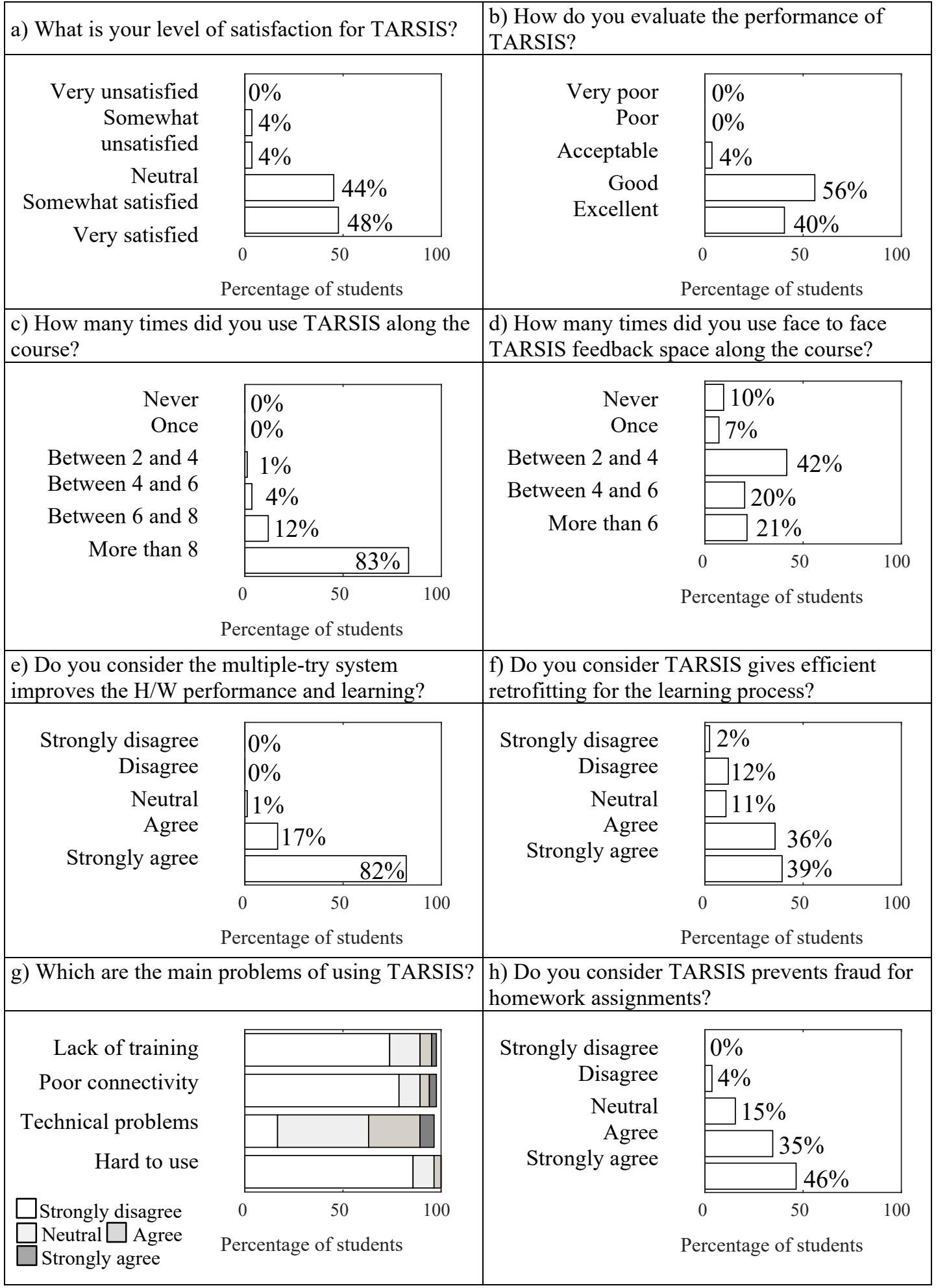

Figure 6. Statistical results regarding several aspects of TARSIS methodology.

\section{Motivation}

One of the main objectives of this study was to understand what motivates students to use the TARSIS methodology. We identified the following three groups of reasons that explain why the TARSIS methodology stimulates homework assignment development among students: (1) the attempt system allows students to learn from errors throughout the assignment; (2) the division of problems in sub-steps with real- 
time grading builds confidence in the students' learning process, and helps them to identify specific knowledge gaps; and (3) the assignation of different problems to each student decreases fraud. Data indicates that students were fully aware of the principles of the pedagogical design of TARSIS. First, the attempt system was designed to avoid the mere effort of the students to be focused on obtaining a grade, motivating its use as a learning tool. Students in the focus group recognised this, as some of them recalled (all comments were originally in Spanish):

This system is priceless since fosters the learning in an efficient way, by given the tools and attempts to identify errors in the development of typical problems in structural engineering.

This system is important because it is based on an innovative way of assessing homework, in which one is able to learn from errors. By having the chance of auto-assessing one can spot our own failures; hence, the student is capable of improving and obtaining better grades in examinations.

Since the homework problems were divided into items (sub-steps) with real time grading, students could check their errors in a didactical way. This feedback prevented students from continuing propagating errors from previous steps within the proposed solution, which are hard to track later once the problem is fully solved. We developed the item system to offer the opportunity to easily spot errors in order to generate a more autonomous learning environment. Students in the focus group agreed with these ideas. For example:

By using this platform, one can find out, very specific, where the errors are, so one can work progressively until all the steps are clear in a problem. I am very sure that without this system, I would not be allowed to understand my errors and learn.

Additionally, we intended to tackle the fraud phenomenon by creating a system that effectively assigned a different problem to each student thanks to a massive bank of questions. Students highlighted that the methodological approach heavily decreased fraud, fostering individual work. Two students stated, for instance:

It is a valuable alternative that offers a learning way that allow us to develop the homework assignments individually without the possibility of fraud.

It promotes learning based on motivation for the process instead towards obtaining a grade, which decreases the chance of falling in fraud with other students.

\section{Assistance}

According to the interviewed teachers, the assistance strategy was designed and implemented in such way that students could obtain virtual and face-to-face support without repercussion in their homework assignment grades. Four class monitors, two teacher assistants, and two professors were available to answer, both face-to-face and online questions about problems or concepts, aiming to offer the most effective and efficient mechanism of assistance. Approximately 8 hours per week was dedicated to feedback. Students were emphatic about the importance of assistance as a base ground characteristic of the pedagogical innovation. Of the students who answered the open question, "describe in detail your assistance experience as positive or negative", 91.5\% manifested they solved all their questions and successfully finished their homework assignments after assistance. Two students described their experience as follows:

My experience was very favorable given that all my emails were answered quickly, and the face-to-face hours were beneficial for the moments I felt stuck.

I only used the email channel to solve questions regarding concepts and the functions of the TARSIS platform. In both cases, the assistance was exceptional and very fast. Class monitors and teacher assistants are very kind in resolving specific questions and clarifying methods. They took into account all the comments I made; hence, I always felt I had someone backing me up. My experience was very favorable, and in my opinion, they should expand this system to other classes. 
A critical characteristic of TARSIS methodological approach relies on the fact that the teacher assistants' and class monitor's time is almost exclusively aimed at face-to-face support. Since the platform automatically grades all problems, no manual labor is needed, freeing an extensive amount of time from the teaching team to actually assists students. One student recalled:

I was impressed by the availability of the class monitors. Since multiple homework assignments required the use of SAP 2000 framework, which is a difficult software to use, I used several times the office hours of attention to get help with the software.

\section{Repercussion in learning}

The relevance of performing pedagogical innovations regarding homework assignments in the structural analyses course was, ultimately, to deploy a robust strategy to increase the learning outcomes for students. The strategy relied on a strong integration between knowledge and technology, in order to create an environment in which students could perceive homework assignments as valuable and motivating learning resources. Data indicates that students recognised the main pedagogical axes of the innovation as promoters of learning. Students manifested that the pedagogical approach encouraged a conscious and motivated development of homework assessments, triggered by the attempt system, real-time feedback, and assistance. A conscious and motivated engagement in homework assignments led to a deeper understanding of concepts and procedures that profoundly impacted the overall grades. As recounted by two students:

I consider that TARSIS contributes to my learning process due that allows me to consolidate knowledge in an innovative way, which I had never experienced in other courses before. I was successful not only because of its interface but because of its immediate feedback and assistance system.

I definitely consider that TARSIS contributes to my learning process. The modality of attempts that is proposed, the problems provided, and the time involved in carrying out each of the homework assignments, motivates the student to invest a greater amount of time in studying the topics. Thanks to this sort of strategies, one can develop skills in a better way, bringing a great benefit to the students.

\section{Discussion}

The study design herein described was used to determine whether the deployment of TARSIS methodology stimulated that the learning outcomes were addressed throughout the course. Following a quantitative evaluative approach, data shows a statistical difference regarding the performance in the course by using the TARSIS methodological approach. Triangulation of data indicates that this increase in performance heavily relied on the attempt system designed, as students were motivated to embrace homework assignments as opportunities for learning, instead of merely mechanisms to obtain additional grades. Data retrieved in this study provides an initial starting point that indicates that our pedagogical design successfully engaged students in the conscious development of homework assignments, as the subdivision and the individual assignment of problems system resulted in a more enthusiastic attitude from the students' perspective.

Such an increase in motivation and engagement can be explained by the concepts of reification and participation proposed by (Wenger, 1998). Regarding the former, the process of successfully converting abstract concepts seen in class into artifacts (in the case of homework assignments, numbers resulting from consciously solving problems) clarifies and raises awareness in students about what they are effectively learning. Conversely, as the pedagogical design allowed students to identify unsuccessful actions without penalty in their homework assignment, students were able to obtain specific insights into their errors in order to avoid known pitfalls (Agouridas \& Race, 2007). By recognising and learning from errors, students could perform reification in terms of converting failed experiences into mechanisms of learning.

This pedagogical approach increased participation via a three-fold approach. First, students were engaged in the use of specialised knowledge, artifacts, and language forms from the civil engineering community by developing homework assignments consciously. Such interactions provided a scenario for the formation of identity among students, a process that profoundly impacts the process of learning (Radford, 2008; Roth, 2009). Second, such level of participation in homework assignments was the result of an innovative 
pedagogical approach framed by a robust e-learning environment. Via the TARSIS methodology, there is no cognitive overload for learners and the problems were highly relevant for the development of the course, resulting in high engagement of students (Perera, 2010; Ping, 2004). Lastly, students were able to interact virtually or face-to-face in a non-class environment with class monitors, teaching assistants, and professors, with a wide variety of available times during the week. This sort of interaction turns into forms of active participation, as students are empowered to decide when the assistance is needed.

Overall, our pedagogical approach was recognised as a mechanism for active learning among students and teachers. The design, implementation, and assurance of this methodology delivers carefully designed activities that promote active reification and participation processes. When reification and participation practices interact in a well-balanced design, a negotiation of the meaning environment is generated, allowing students to build new knowledge and acquire or enhance skills (Radford, 2008). In this sense, the development of homework assignments changed from a traditional passive teacher-centered strategy to an active student-centered strategy, empowering students to manage their time, strategies, and resources for effective learning. Furthermore, qualitative data indicated that students recognised the professor's presence as a critical resource for active learning. As proposed by Northedge (2002), students might get engaged in the use of specialised knowledge only if the professor assumes the role of a representative member of a specialised community who guides learning processes. Therefore, the role of the teaching team in the pedagogical approach described changes from their traditional position of knowledge possessors, to a more dedicated guide in the students' learning process. By performing such a fundamental change, the teaching team becomes a bridge that facilitates the transition in the students from colloquial ways of explaining structural analysis phenomena, to a specialised way of civil engineering thinking.

\section{Conclusions}

Combining e-learning environments with homework assignments may produce students' disengagement to the learning objectives due to loss of motivation, cognitive overload, or diminished relevance of the taught concepts. Additionally, such environments may affect socio-cultural characteristics required for active learning, due to lack of socialisation and a decrease in face-to-face interactions. Therefore, students might envision homework assignments as a process unattached to the pedagogical scheme required for a learning process. To solve these issues, we proposed a pedagogical methodology called TARSIS, which includes socio-cultural aspects for teaching and learning accompanied by an online platform for homework assignments development. Such innovation allows students to reflect upon their errors without any repercussion in grades, discourages fraud, and provides active interactions through assistance to students (virtual or face-to-face). Overall, the TARSIS methodology improved students' performance measured in a reduction of the proportion of failing students, as well as a remarkable increase in the high performance group compared to a traditional methodology. Additionally, qualitative data demonstrated that students were conscious of how the methodology positively influences their process of learning. The self-paced process fostered by TARSIS not only encouraged students to obtain better grades, but also allowed them to gain confidence and a deeper understanding of the procedures and concepts.

Behind the success of the TARSIS methodology, there are socio-cultural concepts that support the pedagogical strategy. Learning as a process implies that students were conscious of limitations they encountered and relied on interactions with the academic team to overcome them. Since reification (consciousness) and participation (interaction) processes were articulated throughout the development of homework assignments, students were able to successfully construct significant meaning. Educational theories transformed into interventions profoundly impacted students' performance, as professors could evaluate innovative approaches and theorise about the results obtained. Therefore, we encourage professors and staff to actively use this pedagogical methodology for its deployment in courses not only related to engineering, but also in courses from an extended range of disciplines.

\section{Limitations to the study}

Statistical power could be enhanced by a larger sample from future cohorts for a longitudinal analysis to provide a definitive final statement about the scope of the approach herein described. A larger sample might find significant differences that could support improvements in the performance related to homework assignments. Moreover, data could be enhanced by determining linearity between specific homework assignments and midterm exams, in order to establish how well each of the homework assignments directly impacts the performance of students in written tests. Such analysis unfortunately is not available at this 
time since problems in homework assignments do not overlap specifically with the structure of midterm examinations.

\section{Future research}

This study has focused on a specific course of the undergrad civil engineering program of our institution. To build a more comprehensive picture of the power of our pedagogical innovation, the TARSIS methodology should be implemented in other courses not only related to civil engineering, but to a wide range of disciplines. At this very moment there are ongoing discussions to implement our methodology in courses belonging to the math and physics departments by mid 2020. Data from different disciplines might enhance the analysis of the scope and limitations of our innovation, as well as could provide a more general framework for the successful inclusion of active learning in homework assignments. Furthermore, it would be beneficial to determine the degree to which technical issues could affect student performance, as closedended questions highlight some responses regarding the TARSIS platform stability.

\section{Acknowledgments}

This project was funded by the School of Engineering at Universidad de los Andes (Colombia); gratitude is extended to Alvaro Galvis, Ricardo Calle, Sergio Bustos and all the members of the Conecta-TE Center (https://conectate.uniandes.edu.co/) who made the TARSIS project possible. The authors are also grateful to Doctors Eduardo Behrentz and Alfonso Reyes, former and current deans of the School of Engineering, respectively; as well as to Juan N. Villamizar, Catalina Gonzalez, and Andres F. Calvo for preparing TARSIS problems.

\section{References}

Agouridas, V., \& Race, P. (2007). Enhancing knowledge management in design education through systematic reflection practice. Concurrent Engineering: Research and Applications, 15(1), 63-76. https://doi.org/10.1177/1063293X07076267

Bamberger, M. (2012). Evaluation for equitable development results (UNICEF Eva). Retrieved from http://www.clear-la.cide.edu/sites/default/files/Evaluation for equitable results web.pdf

Broadbent, J. (2017). Comparing online and blended learner's self-regulated learning strategies and academic performance. Internet and Higher Education, 33(1), 24-32. https://doi.org/10.1016/j.iheduc.2017.01.004

Carr, R., Palmer, S., \& Hagel, P. (2015). Active learning: the importance of developing a comprehensive measure. Active Learning in Higher Education, 16(3), 173-186. https://doi.org/10.1177/1469787415589529

Clarck, R., \& Maryer, E. (2002). E-Learning and the science of instruction: Proven guidelines for consumers and designers of multimedia learning. West Sussex: John Wiley.

Cooper, H. (2001a). Homework for all-in moderation. Educational Leardership, 58(7), 34-38. Retrieved from http://www.ascd.org/publications/educational-leadership/apr01/vol58/num07/Homework-forAll-in-Moderation.aspx

Cooper, H. (2001b). The battle over homework: Common ground for administrators, teachers, and parents. (2nd ed.). Thousand Oaks, CA:Corwin Press.

Cresswell, J. (2009). Research design: Qualitative, quantitative, and mixed methods approaches. 3rd ed. Thousands Oaks, CA:Sage.

Dziuban, C., Graham, C., \& Moskal, P. (2018). Blended learning: The new normal and emerging technologies. International Journal of Education Technololy in Higher Education, 15(3). https://doi.org/10.1186/s41239-017-0087-5

Fan, H., Xu, J., Cai, Z., He, J., \& Fan, X. (2017). Homework and students' achivement in math and science; A 30-year meta-analysis. Educational Research Review, 20(1), 35-54. https://doi.org/10.1016/j.edurev.2016.11.003

Felder, R. (2007). Sermons for grumpy campers. Chemistry Engineering Education, 41(3), 183-184.

Felder, R., \& Brent, R. (2016). Teaching and learning STEM: A practical guide. San Francisco, CA: Jossey-Bass.

Garrison, D., \& Vaughan, N. (2007). Blended learning in higher education: Framework, principles, and guidelines (1st ed.). San Francisco, CA: Jossey-Bass.

Garrison, D., \& Vaughan, N. (2013). Blended learning in higher education. San Francisco, CA: JosseyBass Print. 
Gomez, L., \& Duart, J. (2011). A hybrid approach to university subject learning activities. British Journal of Educational Technology, 42(2), 259-271. Retrieved from https://dialnet.unirioja.es/servlet/articulo?codigo $=6498421$

Green, J., Bouce, A., \& Ahn, J. (2011). A values-engaged, educative approach for evaluating education programs: A guidebook for practice. Illinois, IL: University of Illinois Publications.

Hailey, E. (2018). Homework without barriers (Master's thesis). California State University Monterey Bay. California, CA. Retrieved from https://digitalcommons.csumb.edu/caps_thes_all/366

Hall, S., Waitz, I., Brodeur, D., Soderholm, D., \& Nasr, R. (2002). Adoption of active learning in a lecture-based engineering class. Proceedings of the 32nd ASEE/IEEE Frontiers in Education Conference, Boston, $M A$.

Harrington, A. (2010). Problematizing the hybrid classroom for ESL/EFL students. The Electronic Journal for English as a Second Language. 14(3), 1-13. Retrieved from http://www.teslej.org/wordpress/issues/volume14/ej55/ej55a3/

Havemann, L., \& Barros, J. (2019). A multitude of modes: Considering 'blended learning' in context. Proceedings of the CDE RIDE Conference, London. Retrieved from http://oro.open.ac.uk/66236/

Heffernan, N. (2019). Don't eliminate homework. Make it more effective. Phi Delta Kappan, 100(6), 8081. https://doi.org/10.1177/0031721719834038

Henkel, M. (2005). Academic identity and autonomy in a changing policy environment. Higher Education, 49(1), 155-176. https://doi.org/10.1007/s10734-004-2919-1

Hernández, C., Ravn, O., \& Valero, P. (2015). The Aalborg university PO-PBL model from a sociocultural learning perspective. Journal of Problem Based Learning in Higher Education, 3(2), 16-35. https://doi.org/10.5278/ojs.jpblhe.v0i0.1206

Kravolec, R., \& Buell, J. (2011). End homework now. Educational Leadership, 58(7), 39-42. Retrieved from http://www.ascd.org/publications/educational-leadership/apr01/vol58/num07/End-HomeworkNow.aspx

Leach, J., \& Scott, P. (2003). Individual and sociocultural views of learning in science education. Science \& Education, 12(1), 91-113. https://doi.org/10.1023/A:102266551

Lecanda, R., \& Garrido, C. (2003). Introducción a la metodología de investigación cualitativa. Revista de Psicodidáctica Bilbao, 14(1), 5-40. Retrieved from http://www.redalyc.org/articulo.oa?id=17501402

Lim, D., \& Morris, M. (2009). Learner and instructional factors influencing learning outcomes within a blended learning environment. Educational Technology \& Society, 12(4), 282-293. Retrieved from https://www.jstor.org/stable/jeductechsoci.12.4.282

Malgwi, C., \& Rakovski, C. (2009). Combating academic fraud: Are students reticent about uncovering the covert? Journal of Academic Ethics, 7(1), 207-221. https://doi.org/10.1007/s10805-009-9081-4

MATLAB. (2019). Matlab. Natick, Massachusetts: The MathWorks Inc.

Merriam, S. B., \& Tisdell, E. J. (2015). Qualitative research: A guide to design and implementation. San Francisco, CA: John Wiley \& Sons.

Northedge, A. (2002). Organizing excursions into specialist discourse communities: A sociocultural account of university teaching. Wiley Online Library.

Oh, E., \& Park, S. (2009). How are universities involved in blended instruction? Educational Technology \& Society, 12(3). Retrieved from https://eric.ed.gov/?id=EJ857449

Oliver-Hoyo, M., \& Allen, D. (2006). The use of triangulation methods in qualitative educational research. Journal of College Science Teaching, 35(4), 42-47. Retrieved from https://eric.ed.gov/?id=EJ752577

Perera, I. (2010). What will users expect from virtual learning methods?-A conceptual model to analyze future leaning method enhancements. US-China Education Review, 7(11), 76-82. Retrieved from https://eric.ed.gov/?id=ED514781

Ping, C. (2004). Engaging learners in online learning environments. Tech Trends, 48(4), 16-23. Retrieved from https://link.springer.com/article/10.1007\%2FBF02763440

Pundak, D., \& Rozner, S. (2008). Empowering engineering college staff to adopt active learning methods. Journal of Science Education and Technology, 17(2), 152-163. https://doi.org/10.1007/s10956-0079057-3

Pundergast, L., Watkins, M., \& Canivez, G. (2014). Structural and convergent validity of the homework performance questionnaire. Educational Psychology: An International Journal of Experimental Educational Psychology, 34(3), 291-304. https://doi.org/10.1080/01443410.2013.785058

Radford, L. (1997). On psychology, historical epistemology, and the teaching of mathematics: Towards a socio-cultural history of mathematics. International Journal of Mathematics Education, 17(1), $26-33$. Retrieved from http://www.jstor.org/stable/40248219

Radford, L. (2008). The ethics of being and knowing: Towards a cultural theory of learning. In L. 
Radford, G. Schubring, \& F. Seeger (Eds.), Semiotics in mathematics education: Epistemology, history, classroom, and culture (pp. 215-234). Rotterdam: Sense Publishers.

Ramdass, D., \& Zimmerman, B. (2011). Developing self-regulation skills: The important role of homework. Journal of Advanced Academics, 22(2), 194-218. https://doi.org/10.1177/1932202X1102200202

Roth W. M. (2009). The gap between university and the workplace. In O. Skovsmose, P. Valero, \& O. R. Christensen (Eds.) University science and mathematics education in transition (pp. 133-162). Boston, MA: Springer.

Roth, W. M., \& Lee, S. (2004). Science education as/for participation in the community. Science Education, 88(2), 263-291. https://doi.org/10.1002/sce.10113

Schunk D. H. (2001). Social cognitive theory and self-regulated learning. In B. J. Zimmerman, \& D. H. Schunk (Eds.). Self-regulated learning and academic achievement. Springer series in cognitive development (pp. 83-98). New York, NY: Springer.

Sutherland, L., Scanlon, L., \& Sperring, A. (2005). New directions in preparing professionals: Examining issues in engaging students in communities of practice through a school-university partnership. Teahing and Teacher Education, 21(1), 79-92. https://doi.org/10.1016/j.tate.2004.11.007

Tashakkori, A., \& Teddle, C. (2002). Handbook of mixed methods in social and behavioral research. Thousand Oaks, CA: Sage.

Tayebinik, M., \& Puteh, M. (2012). Blended learning or e-learning? International Magazine on Advances in Computer Science and Telecommunications, 3(1), 103-110. Retrieved from https://arxiv.org/abs/1306.4085

Vygotsky, L. (1978). Mind in society. Cambridge, MA.: Harvard University Press.

Wenger, E. (1998). Communities of practice: Learning meaning and identity. Cambridge, MA: Cambrigde University Press.

Wertsch, J. (1985). Vygotsky and the social formation of mind. Cambridge, MA: Harvard University Press.

Xu, M., Benson, S., Mudrey-Camino, R., \& Steiner, R. (2010). The relationship between parental involvement, self-regulated learning, and reading achievement of fifth graders: A path analysis using the ECLS-K Database. Social Psychological Education, 13(2), 237-269. https://doi.org/10.1007/s11218-009-9104-4

Zare, R., Cox, C., Murphy, K., \& Bayas, C. (2017). Implementation of peer-reviewed homework assignments. Journal of College Science Teaching, 45(3), 40-46. Retrieved from https://web.stanford.edu/group/Zarelab/publinks/948.pdf

Corresponding author: Francisco Buitrago-Flórez, sicks@uniandes.edu.co

Copyright: Articles published in the Australasian Journal of Educational Technology (AJET) are available under Creative Commons Attribution Non-Commercial No Derivatives Licence (CC BY-NCND 4.0). Authors retain copyright in their work and grant AJET right of first publication under CC BYNC-ND 4.0.

Please cite as: Buitrago-Flórez, F., Reyes, J. C., Rincón, R., Hernández, C., Galvis, F., \& Ángel, C. (2020). Engaging in homework development: TARSIS platform as an innovative learning methodology. Australasian Journal of Educational Technology, 36(3), 147-162.

https://doi.org/10.14742/ajet.5865 